\title{
Developmental Changes in Synaptic Distribution in Arcuate Nucleus Neurons
}

\author{
Arian F. Baquero, ${ }^{-}$Melissa A. Kirigiti, Karalee C. Baquero, Shin J. Lee, $₫$ M. Susan Smith, and Kevin L. Grove \\ Division of Diabetes, Obesity, \& Metabolism, Oregon National Primate Research Center (ONPRC), Beaverton, Oregon 97006
}

\begin{abstract}
Neurons coexpressing neuropeptide Y, agouti-related peptide, and GABA (NAG) play an important role in ingestive behavior and are located in the arcuate nucleus of the hypothalamus. NAG neurons receive both GABAergic and glutamatergic synaptic inputs, however, the developmental time course of synaptic input organization of NAG neurons in mice is unknown. In this study, we show that these neurons have low numbers of GABAergic synapses and that GABA is inhibitory to NAG neurons during early postnatal period. In contrast, glutamatergic inputs onto NAG neurons are relatively abundant by P13 and are comparatively similar to the levels observed in the adult. As mice reach adulthood (9-10 weeks), GABAergic tone onto NAG neurons increases. At this age, NAG neurons received similar numbers of inhibitory and EPSCs. To further differentiate age-associated changes in synaptic distribution, 17- to 18-week-old lean and diet-induced obesity (DIO) mice were studied. Surprisingly, NAG neurons from lean adult mice exhibit a reduction in the GABAergic synapses compared with younger adults. Conversely, DIO mice display reductions in the number of GABAergic and glutamatergic inputs onto NAG neurons. Based on these experiments, we propose that synaptic distribution in NAG neurons is continuously restructuring throughout development to accommodate the animals' energy requirements.
\end{abstract}

Key words: arcuate; development; NAG neurons; obesity; synaptic inputs

\section{Introduction}

Two populations of neurons in the arcuate nucleus of the hypothalamus (ARH) play an essential role in the regulation of energy homeostasis: proopiomelanocortin peptide (POMC) neurons, and neurons coexpressing NPY/AgRP/GABA (NAG). NAG neurons are considered critical regulators of feeding and food-seeking behavior (Krashes et al., 2011; Atasoy et al., 2012). Conversely, ablation of NAG neurons in adulthood leads to starvation by a suppression of food consumption (Gropp et al., 2005; Luquet et al., 2005). Activation of POMC neurons in mice, however, suppresses feeding and reduces body weight (Aponte et al., 2011). Both NAG and POMC neurons send axonal projections into the paraventricular nucleus of the hypothalamus (PVH) to regulate food intake (Jobst et al., 2004). Recent studies using optogenetics and pharmacogenetics have supported this hypothesis; for example, activation of NAG neurons led to rapid stimulation of feeding through its actions in the PVH (Atasoy et al., 2012; Krashes et al., 2013).

It is well understood that NAG neurons are regulated by hormones, nutrient signals, and synaptic transmission. NAG neu-

Received Jan. 7, 2015; revised April 7, 2015; accepted April 29, 2015.

Author contributions: A.F.B., M.S.S., and K.L.G. designed research; A.F.B., M.A.K., K.B., and S.J.L. performed research;A.F.B., K.B., M.S.S., and K.L.G. contributed unpublished reagents/analytic tools; A.F.B., K.C.B., S.J.L., M.S.S., and K.L.G. analyzed data; A.F.B., M.A.K., K.C.B., M.S.S., and K.L.G. wrote the paper.

This work was supported by Grants P51 0D011092 (ONPRC), R01 HD014643 (M.S.S.), and R01 DK079194 (K.L.G.), and the American Diabetes Association Grant 7-13-MI-06 (A.F.B., K.L.G.). We thank Dr Anda Cornea, and the Imaging and Morphology Core for advice in image analysis.

The authors declare no competing financial interests.

Correspondence should be addressed to Dr Arian F. Baquero, Division of Diabetes, Obesity, \& Metabolism, Oregon National Primate Research Center, 505 NW $185^{\text {th }}$ Avenue, L584, Beaverton, OR 97006-3448. E-mail: baqueroa@ohsu.edu.

DOI:10.1523/JNEUROSCI.0058-15.2015

Copyright $\odot 2015$ the authors $\quad 0270-6474 / 15 / 358558-12 \$ 15.00 / 0$ rons receive direct GABAergic (inhibitory) and glutamatergic (excitatory) inputs from others areas of the hypothalamus (Vong et al., 2011; Krashes et al., 2014). Recent evidence suggests that regulation of synaptic transmission onto NAG neurons plays a role in the central control of energy homeostasis (Zeltser et al., 2012). For instance, during fasting, glutamatergic inputs onto NAG neurons are increased to provide an orexigenic drive. As energy replenishment occurs, the number of EPSCs and dendritic spines is reduced in NAG neurons (Yang et al., 2011; Liu et al., 2012). These data suggest that nutrients and hormones can change firing rates of NAG neurons to regulate feeding behavior and body weight. Indeed, leptin-deficient mice have an increase in EPSCs onto NAG neurons (Pinto et al., 2004). Furthermore, synaptic inputs onto NAG neurons are decreased by chronic consumption of calorically dense diets (Horvath et al., 2010). Although modulation of synaptic transmission can alter the function of NAG neurons in the adult, the question remains as to what happens during development.

Pups make a transition from suckling to autonomic feeding behavior during postnatal development. Around P13, rodents initiate ingestion of solid food, and by P21 they are capable of sustaining independent feeding behavior (Swithers, 2003). In the present study, we characterized synaptic inputs onto NAG neurons during these critical periods of development. We also investigated synaptic plasticity in NAG neurons through the first 5 months of the animal's life. Finally, we examined the effects of diet-induced obesity (DIO) in the organization of EPSCs and IPSCs onto NAG neurons. Our results support the idea that glutamatergic and GABAergic synaptic inputs onto NAG neurons are rapidly restructured to accommodate energy demands throughout the animals' life. 


\section{Materials and Methods}

Animals. NPYhrGFP mice were purchased from The Jackson Laboratory for breeding. Litters of six to nine pups were born normally, and pups were genotyped to identify expression of green fluorescent protein (GFP) under the control of the mouse NPY promoter. NPYhrGFP+ mice were used in all experiments and were weaned at P21. After weaning, only male mice were used in our studies. Mice were group-housed (4 per cage) and maintained under a $12 \mathrm{~h}$ light/dark cycle (lights on 7:00 A.M.). Standard chow diet (Purina lab chow no. 5001) and water were available ad libitum. To generate DIO mice, a separate cohort of NPYhrGFP+ mice were fed ad libitum with 60\% High Fat Diet (HFD; Research Diets; catalog \#D12492) after P30 for a minimum of 12 weeks (Lee et al., 2013). Animals for all studies were killed $1 \mathrm{~h}$ after lights on. Animal procedures were approved by the Oregon Health and Science University Institutional Animal Care and Use Committee.

Drugs. Biocytin and GABA were purchased from Sigma-Aldrich. Bicuculline, 6-cyano-7-nitroquinoxaline-2,3-dione (CNQX), DL-2-amino5-phosphonovaleric acid (APV), baclofen were obtained from Tocris Bioscience, and tetrodotoxin (TTX) from Alomone Labs.

Electrophysiology. All recordings were performed in NPY-GFP + neurons in the ARH at the following ages: P13-P15, P21-P23, 9-10 weeks, and 17-18 weeks. Coronal slices containing ARH were prepared as previously described (Qiu et al., 2010). Briefly, brain slices (300 $\mu \mathrm{M})$ containing ARH were maintained with constant flow $(1-2 \mathrm{ml} / \mathrm{min})$ of artificial CSF (aCSF) containing the following (in $\mathrm{mm}$ ): $124 \mathrm{NaCl}, 5 \mathrm{KCl}$, $2.6 \mathrm{NaH}_{2} \mathrm{PO}_{4}, 1 \mathrm{MgSO}_{4}, 1 \mathrm{CaCl}_{2}, 26 \mathrm{NaHCO}_{3}, 10 \mathrm{HEPES}, 10$ glucose; oxygenated $\left(95 \% \mathrm{O}_{2}, 5 \% \mathrm{CO}_{2}\right)$ osmolarity $\sim 305$ at $32-33^{\circ} \mathrm{C}$. IPSCs were recorded at a holding potential of $-60 \mathrm{mV}$ in whole-cell patch-clamp mode. Pipettes have a resistance of $2-4 \Omega \mathrm{M}$ when filled with a cesium chloride-based solution containing the following (in $\mathrm{mm}$ ): $140 \mathrm{CsCl}, 5$ $\mathrm{MgCl}_{2}, 1$ BAPTA, 5 ATP, 0.3 GTP, biocytin $2 \%$, pH $\sim 7.35$ with $\mathrm{CSOH}$, osmolarity $\sim 295$. APV $(50 \mu \mathrm{M})$ and CNQX $(10 \mu \mathrm{M})$ were added into the bath to isolate IPSCs. TTX $(1 \mu \mathrm{M})$ was added into the bath to isolate miniature IPSCs (mIPSCs).

EPSCs were recorded with a cesium-methanesulfonate-based solution containing the following (in mM): $125 \mathrm{CsMeSO}_{3}, 10 \mathrm{CsCl}, 5 \mathrm{NaCl}, 2$ $\mathrm{MgCl}_{2}, 10$ HEPES, 1 EGTA, 5 ATP, 0.3 GTP, biocytin $\%$, pH $\sim 7.35$ with $\mathrm{CSOH}$, osmolarity $\sim 295$. Pipettes have a resistance of $2-4 \Omega \mathrm{M}$ and neurons were held at $-60 \mathrm{mV}$ in whole-cell patch-clamp mode. Bicuculline $(5 \mu \mathrm{M})$ was added into the bath to block IPSCs. TTx $(1 \mu \mathrm{M})$ was added into the bath to isolate miniature EPSCs (mEPSCs). Series resistance values were generally $<20 \mathrm{M} \Omega$ during the experiments. Data analysis was performed using clampfit 10 and only synaptic events $>5 \mathrm{pA}$ were analyzed. Following IPSC or EPSC recordings, pipettes were slowly withdrawn from the neurons for postrecording immunohistochemistry studies.

For current-clamp experiments, microelectrodes had resistances of 3-5 $\Omega \mathrm{M}$ and were filled with an internal solution containing the following (in mM): $127 \mathrm{~K}$-gluconate, 10 EGTA, 5 HEPES, 4 ATP, 0.3 GTP, $\mathrm{pH} \sim 7.25$ with $\mathrm{KOH}$, osmolarity $\sim 295$. The liquid junction potential of $-5 \mathrm{mV}$ was corrected in the analysis. Data acquisition was performed using a multiclamp 700B amplifier (Molecular Devices). Data were sampled at $20 \mathrm{kHz}$ using a computer interface Digidata 1322 and pClamp 9.2 software (Molecular Devices).

Vesicular GABA transporter immunohistochemistry. Following IPSC recordings, immunohistochemistry for vesicular GABA transporter (VGAT) was performed as previously described (Melnick et al., 2007). Briefly, brain slices from P13-P15, P21-P23, 9-10 weeks, and 17-18 weeks were fixed in phosphate-buffered $4 \%$ paraformaldehyde (PFA), $\mathrm{pH} 7.4$, for $24 \mathrm{~h}$ at $\left(4^{\circ} \mathrm{C}\right)$. Fixed slices from all ages were rinsed in potassium PBS (KPBS) and then blocked in $2 \%$ NDS/0.4\% Triton-X in KPBS for $30 \mathrm{~min}$. Sections were incubated for $1 \mathrm{~h}$ at $\mathrm{RT}$ and $72 \mathrm{~h}$ at $4^{\circ} \mathrm{C}$ in Rb-anti-VGAT (Millipore, catalog \#AB5062P) at 1:4000. After $48 \mathrm{~h}$, fresh primary antibody solution was added into the brain slices. Slices were then rinsed in KPBS and incubated in secondary antibodies, donkey-anti-rabbit AlexaFluor 647 (1:1000 for VGAT) and donkey-anti-rabbit streptavidinAlexaFluor 568 (1:5000, to visualize postrecording biocytin-filled neurons) for $2 \mathrm{~h}$.
VGLUT2 immunohistochemistry. Following EPSC recordings, immunohistochemistry for vesicular glutamate transporter 2 (VGLUT2) was performed with a similar protocol as described above (Melnick et al., 2007). Briefly, brain slices containing NPY-filled cells from P13-P15, P21-P23, 9-10 weeks, and 17-18 weeks were fixed and incubated in Rb-anti-VGLUT2 (Synaptic Systems, catalog \#35402) at 1:1000. Secondary antibodies were donkey anti-rabbit AlexaFluor 647 (1:1000 for VGLUT2) and anti-rabbit streptavidin-AlexaFluor 568 (1:5000 to visualize postrecording biocytin-filled neurons).

Image analysis of juxtaposed GABAergic or glutamatergic terminals on NAG neurons. Immunostained sections were imaged on a laser scanning confocal microscope (Leica TCS SP) equipped with a $63 \times$ glycerolcorrected objective. All images of NPY-GFP (using a $488 \mathrm{~nm}$ AR laser), biocytin-filled cells (using a $561 \mathrm{~nm}$ DPSS laser), VGAT, or VGLUT2 (using a $633 \mathrm{~nm}$ HeNe laser) were taken at $1 \mu \mathrm{m}$ increments along the $z$-axis of the tissue. Each wavelength was imaged sequentially to avoid bleed-through of different fluorophores.

To determine the number of juxtaposed GABAergic or glutamatergic terminals on NPY-biocytin-filled neurons, we used ImageJ software (NIH) as follows: (1) The area of $\sim 900$ randomly selected VGAT-labeled or VGLUT2-labeled synaptic boutons were manually measured from three pups (P13-P15), three young adults (9-10 weeks), and three lean adults (17-18 weeks). Furthermore, the circularity of VGAT- or VGLUT2-labeled synaptic boutons was calculated using the following formula:

$$
\text { Circularity }=4 \pi \times \frac{[\text { area }]}{[\text { perimeter }]^{2}}
$$

A value of 1.0 with this circularity formula indicates a perfect circle. Under this analysis, there was no significant difference in either circularity or area of VGAT-labeled or VGLUT2-labeled synaptic boutons across all ages (Fig. $1 A, B$ ). (2) Images were binarized and added together with the image calculator function. (3) The size and circularity of the calculated range for VGAT- or VGLUT2-labeled synaptic boutons were set in the analysis of particles function to determine closely apposed boutons in the proximal processes of NPY-biocytin filled neurons. (4) Each optical section containing possible appositions was checked visually to verify the accuracy of this quantitative procedure. The number of VGAT or VGLUT2 appositions was normalized to a set distance of biocytin-filled proximal process $(1 \mu \mathrm{m})$.

To determine the overall density of VGAT and VGLUT2 boutons in the ARH, we analyzed only the $633 \mathrm{~nm}$ HeNe laser images. Each VGATor VGLUT2-labeled synaptic bouton was defined as three-dimensional object (voxel to voxel). The ratio of labeled synaptic boutons for VGAT or VGLUT2 was obtained by dividing the average density of each age to the average density of P13-P15.

DiI implants in postnatal mice: Both male and female pups from NPYhr-GFP mice at P15 and P21 were anesthetized and perfused transcardially with saline followed by ice-cold 4\% PFA, pH 7.4. Perfused brains were removed immediately and stored in fixative at $4^{\circ} \mathrm{C}$ until they could be blocked and embedded in 3\% agarose. Embedded brains were sectioned coronally rostral to caudal to expose the dorsal medial hypothalamus (DMH). The surface of each block was stained with methylene blue to visualize neuroanatomical features. A small crystal of DiI $(1,1-$ dioctadecyl-3,3,3,3-tetramethylindo carbocyanine perchlorate; Invitrogen) was placed unilaterally into the $\mathrm{DMH}$ of each brain under a dissection scope. Implanted brains were stored in $4 \% \mathrm{PFA}$ at $37^{\circ} \mathrm{C}$ for 3 weeks. After the diffusion period, $50 \mu \mathrm{M}$ coronal slices were cut through the hypothalamus using a Vibratome (Leica VT1000S). Hypothalamic sections were mounted onto gel-subbed glass slides and coverslipped with slowfade (Invitrogen). Before mounting sections were incubated with DAPI (1:4000) for 1 min. Hypothalamic slices containing DMH or ARH were imaged on a Leica laser scanning confocal microscope using a $488 \mathrm{~nm}$ AR laser for NPY-GFP, a $561 \mathrm{~nm}$ DPSS laser for DiI, and a 405 $\mathrm{nm}$ laser for DAPI.

$q P C R$. Micropunches from the ARH were collected from 10 animals at ages P12-P13. We combined two animals per tube and isolated RNA using Trizol and the RNeasy micro kit with on-column deoxyribonu- 
A
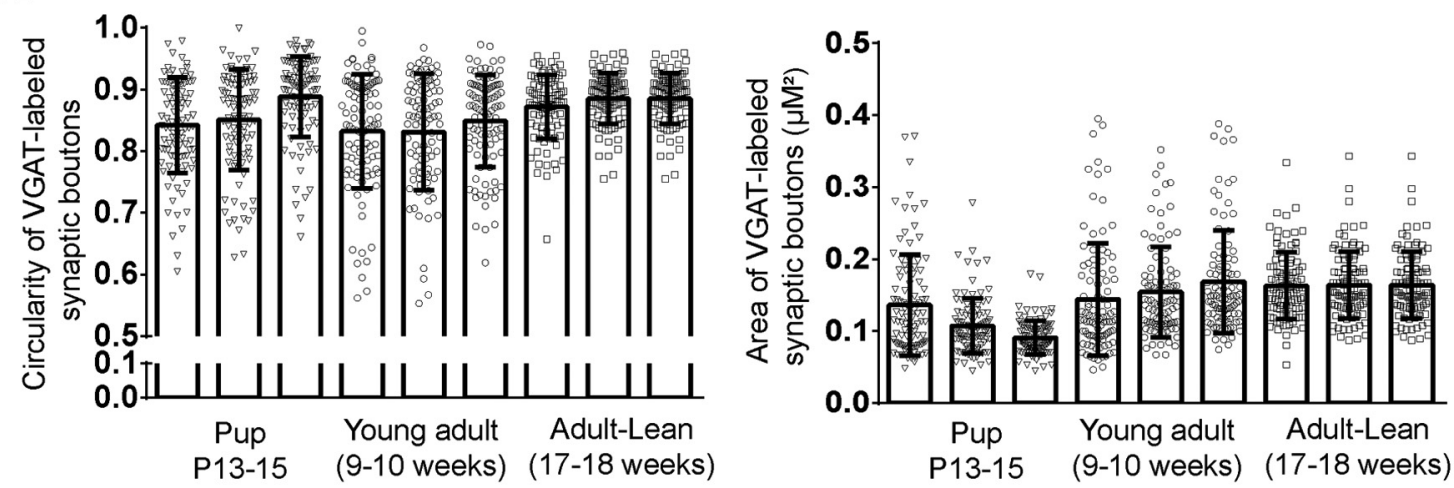

B
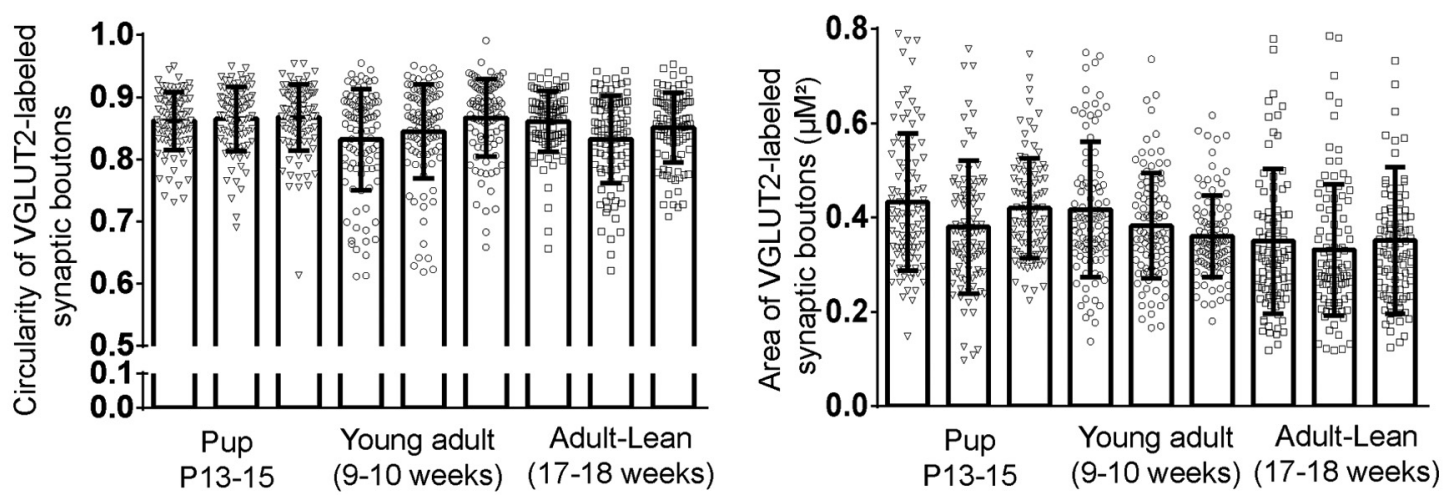

Figure 1. Comparison of circularity and area of synaptic boutons in NAG neurons. $A$, Quantification of circularity and area of VGAT synaptic boutons ( $n=6-8$ optical sections per animal from 9 animals). $\boldsymbol{B}$, Quantification of circularity and area of VGLUT2 synaptic boutons ( $n=6-8$ optical sections per animal from 9 animals). Error bars indicate mean \pm SEM.

clease I treatment (Qiagen). Quality and integrity of RNA was determined using the Agilent 2100 Bioanalyer (Agilent Technologies). Reverse transcriptase reactions were prepared using $300 \mathrm{ng}$ of RNA and iScript cDNA Synthesis Kit (Bio-Rad). Quantitative real-time PCR was completed using TaqMan probes (Applied Biosystems) for NKCC1 (Mm01265951_m1), KCC2 (Mm00803929_m1), and housekeeping gene $\beta$-actin (Mm00607939_s1) was used as an endogenous control to normalize each sample and gene. PCRs were in a $10 \mu \mathrm{l}$ volume using 0.5 $\mu \mathrm{l}$ TaqMan probe, 6 ng cDNA template, $5 \mu \mathrm{l}$ TaqMan Gene Expression Master Mix II with UNG (Applied Biosystems), and 2.5 $\mu$ l DNase/RNase molecular grade water (Qiagen). Real-time PCR was run using an Applied Biosystems 7900HT Fast Real-Time PCR system with an initial denaturing at $50^{\circ} \mathrm{C}$ for $2 \mathrm{~min}, 95^{\circ} \mathrm{C}$ for $10 \mathrm{~min}$, followed by 40 cycles at $95^{\circ} \mathrm{C}$ for $15 \mathrm{~s}$, and annealing at $60^{\circ} \mathrm{C}$ for $1 \mathrm{~min}$. Results were calculated by the relative standard curve method.

Data analysis. All data are expressed as means \pm SEM. Statistical comparisons were performed using paired, unpaired $t$ tests, and ANOVA as appropriate. Bonferroni correction and Tukey's test were used for post hoc analysis; $p<0.05$ was considered significant.

\section{Results}

Development of inhibitory synaptic transmission on NAG neurons in the ARH

To characterize changes in synaptic inhibitory inputs onto NAG neurons during development, we recorded spontaneous IPSCs (sIPSCs) at P13-P15, P21-P23, and 9-10 weeks (denoted as young adult). In all recordings, ARH-NPY-GFP+ neurons were selected at random and held at $-60 \mathrm{mV}$ under voltage-clamp mode. Glutamate receptor blockers, APV $50 \mu \mathrm{M}$ and CNQX 10 $\mu \mathrm{M}$, were used to isolate sIPSCs (Fig. 2A). At P13, when pups initiate the transition from suckling to solid food (Swithers, 2003), we observed that IPSCs onto NAG neurons were relatively low with a frequency of $<0.2 \mathrm{~Hz}$ (Fig. $2 A, C ; n=10$ cells, 8 animals, ANOVA analysis revealed significant changes in inhibitory synaptic frequency by age: $F_{(2,21)}=11.60, p=0.0004$, this analysis was used for all ages in Fig. 2C). Between P21-P23, when pups are acquiring autonomic feeding behavior, there was an enhancement in the variability of sIPSC frequency suggesting maturation of some neurons. At this age, we observed that some NAG neurons exhibited higher frequency of IPSCs, whereas others remained low (Fig. $2 A, C ; n=7,6$ animals). These results are consistent with reports from other hypothalamic areas (Melnick et al., 2007). In young adults, the amount of inhibitory inputs onto NAG neurons continues to rise. At this age, sIPSC frequency in NAG neurons had increased almost threefold over the preweaning period (Fig. $2 A, C ; n=7,4$ animals, young adult vs P13-P15: $t_{(21)}=4.7, p<0.001$; young adult vs P21-P23: $t_{(21)}=$ $3.1, p<0.01$, ANOVA post hoc Bonferroni correction). There was no difference in the amplitude of IPSCs across ages (data not shown). In agreement with our results in young adults, others have reported similar findings in the ARH of 4- to 8-week-old mice (Pinto et al., 2004).

To evaluate the contribution of mIPSCs, we used TTX ( $1 \mu \mathrm{M})$ to block spontaneously occurring postsynaptic currents. As previously reported, we found that most postsynaptic currents onto NAG neurons were driven by vesicle fusion at the presynaptic terminal, rather than being produced by action potentials in presynaptic neurons (Pinto et al., 2004). Overall, the abundance of mIPSCs in NAG neurons was relatively low between P13-P15 (Fig. $2 B, D ; n=8,8$ animals). As expected, mIPSC frequency increased with age (P21-P23; Fig. $2 B, D ; n=7,6$ animals). In young adults, we found that mIPSC frequency in NAG neurons 
A

P13-15

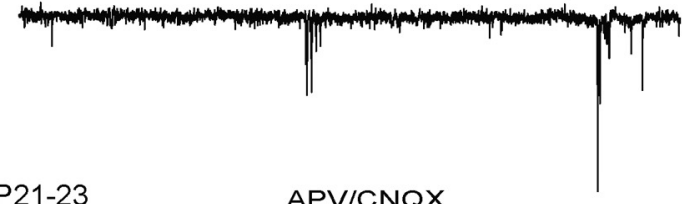

P21-23

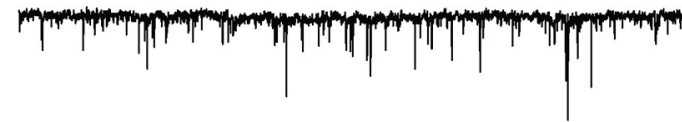

Young adult (9-10 weeks)

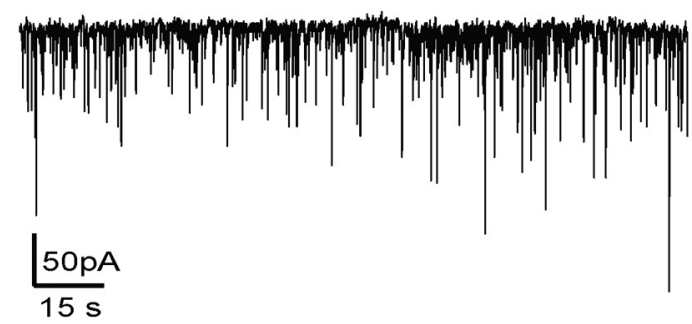

C
APV/CNQX

SIPSC

APV/CNQX

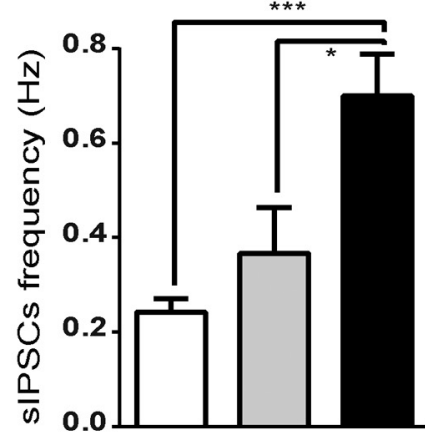

B
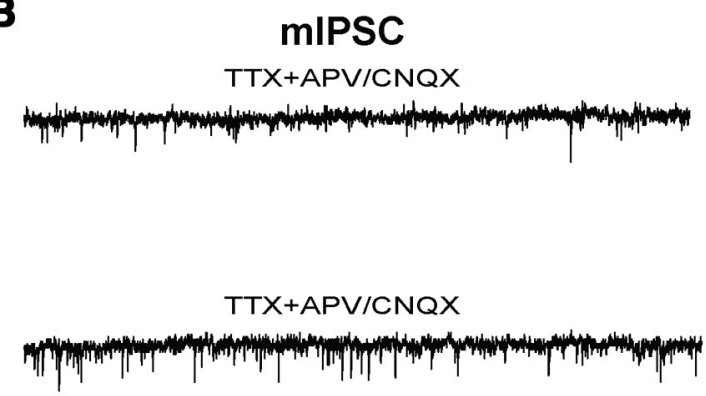

D
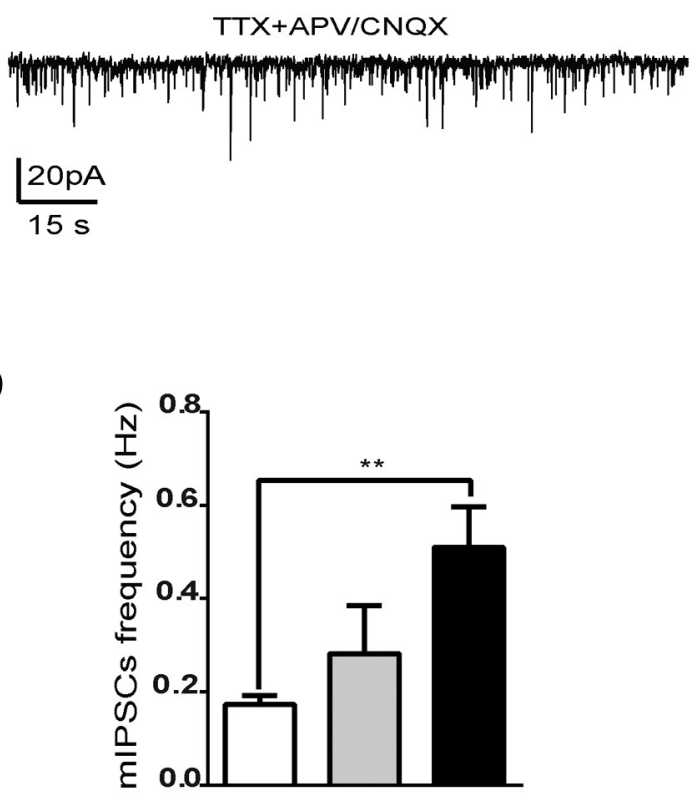

Young adult (9-10 weeks)

Figure 2. Developmental changes in IPSCs in NAG neurons. $\boldsymbol{A}$, Representative traces of spontaneous sIPSCs from ARH-NPY-GFP + neurons under voltage-clamp mode at the following ages: P13-P15, P21-P23, and 9-10 weeks (young adult). $\boldsymbol{B}$, Age-matched representative traces of mIPSCs from ARH-NPY-GFP + neurons. NMDA and AMPA glutamate receptors were blocked with a mixture of APV $(50 \mu \mathrm{m}) / C N Q X(10 \mu \mathrm{m})$. Bar graphs show the mean frequency for sIPSCs $(\boldsymbol{C})$ and $\mathrm{mIPSCs}(\boldsymbol{D})$ in ARH-NPY-GFP + neurons. The number of neurons recorded per age was at P13-P15 (8-10 cells, 8 animals), P21-P23 (7 cells, 6 animals), and young adult (7 cells, 4 animals). Results are shown as mean \pm SEM; ${ }^{*} p<0.05,{ }^{* *} p<0.01,{ }^{* * *} p<0.001$ by AN0VA, post hoc Bonferroni correction.

was significantly higher than in pups (Fig. $2 B, D ; n=7,4$ animals, ANOVA analysis revealed significant difference in MIPSC frequency by age: $F_{(2,19)}=7.3, p=0.004 ; \mathrm{P} 13-\mathrm{P} 15$ vs young adult: $t_{(19)}=3.8, p<0.01$, post hoc Bonferroni correction). These observations are consistent with the idea that orexigenic NAG neurons have a lower inhibitory tone during postnatal development.

To explore this issue, we used an immunohistological approach to characterize the changes in the appearance of inhibitory synapses onto NAG neurons in the ARH. We filled ARH NPY-GFP neurons with biocytin (2\%) during recording, and performed postrecording immunohistochemistry using an antibody against VGAT. We analyzed the area and circularity of VGAT-labeled synaptic boutons from pups to adults. We found that there were no age-dependent differences in VGAT-labeled synaptic boutons across all ages tested (Fig. $1 A, B ; n=6-7$ optical sections, 9 animals; $p>0.05)$. Given these results, we next investigated the number of VGAT appositions on the first $50 \mu \mathrm{M}$ of proximal processes. We determined that synaptic boutons containing VGAT in NAG neurons were relatively low at P13, with a rapid increase by $\mathrm{P} 21$ (Fig. $3 A, B, D$; For P13-P15, $n=2-3$ optical sections, 6 animals, For P21-P23, $n=2-3$ optical sections, 4 animals). However, there were no developmental changes that were significant between P13-P15 and P21-P23 ( $p>0.05)$. In young adults, the number of VGAT appositions in proximal processes of NAG neurons was greater than any other age. However, these results were only significantly different between young adult and P13-P15 mice (Fig. 3C,D; $n=2-3$ optical sections, 6 animals, ANOVA with post hoc Tukey's revealed significant difference in the number of VGAT appositions by age: $F_{(2,23)}=5.5, p<0.011$; young adult vs P13-P15: $\left.q_{(23)}=3.3, p<0.0001\right)$. Furthermore, there was an increase in the density of VGAT-labeled synaptic boutons at P21P23 and in the young adult, but these changes were not significant (Table 1). The observed changes in our immunohistological assays for VGAT correlated well with those seen in IPSC frequency in these neurons.

Development of afferent projections from the DMH to the ARH

It is well established that NAG neurons receive abundant excitatory and inhibitory synaptic inputs in the adult, however, there 
is no current evidence about the development of afferent axonal projections into the ARH (Pinto et al., 2004; Zeltser et al., 2012). Recently, the DMH, which contains both GABAergic and glutamatergic neurons, has been postulated as an upstream regulator of NAG neuronal activity (Krashes et al., 2014). To investigate whether afferent axonal projections from $\mathrm{DMH}$ to the ARH are developed during the third week of postnatal development, we performed DiI implants in the DMH of NPYhrGFP mice at P15 and P21 (Fig. $3 E, H)$. At P15, we observed that most of the labeled fibers were located in a periventricular pathway (Fig. $3 F ; n=5$ animals). While a few scattered labeled fibers have reached the outer edge of the $\mathrm{ARH}$ at this age, there were no fibers observed in the ventral medial region of the ARH where the NPY neurons are located (Fig. 3G). We did observe a few labeled fibers in both the central $\left(\mathrm{VMH}_{\mathrm{C}}\right)$ and dorsomedial $\left(\mathrm{VMH}_{\mathrm{dm}}\right)$ part of ventral medial hypothalamic nucleus (VMH; Fig. $3 F)$ at $\mathrm{P} 15$. By $\mathrm{P} 21$, there was a dramatic increase in the number of labeled fibers extending down into the ARH (Fig. 3I, J; $n=4$ animals). The pathway from DMH to ARH was clearly evident with a number of DiI-labeled fibers mixed together with ARH NPY-GFP+ neurons (Fig. 3J). Together, axonal projections from the $\mathrm{DMH}$ to the ARH developed quickly and appeared to be well established by P21.

\section{Developmental changes of GABA signaling in NAG neurons}

GABA undergoes a functional switch from excitatory to inhibitory during postnatal development. These changes in GABA function are attributed to a decrease in intracellular $\mathrm{Cl}^{-}$concentrations due to a rise in $\mathrm{KCC} 2$ expression, a potassium chloride cotransporter (Chen et al., 1996; Gao and van den Pol, 2001; Sun et al., 2013). To investigate gene expression levels of essential $\mathrm{Cl}^{-}$cotransporters, such as KCC2 and NKCC1 $\left(\mathrm{Na}^{+}{ }_{-}\right.$ $\mathrm{Cl}^{-}-\mathrm{K}^{+}$cotransporter) in NAG neurons, we isolated micropunches from the ARH at P12-P13 and performed qPCR. We found that expression levels for KCC2 were significantly higher than NKCC1 in the ARH, which is expected in mature neurons (Fig. $4 B ; n=6,10$ animals; $t_{(10)}=3.2, p<0.001$, unpaired $t$ test). To examine the functional effects of GABA on NAG neurons during development, we performed current-clamp recordings in ARH NPYGFP + at the following ages: P13-P15, P21-P23, and young adult (9-10 weeks). In all experiments, GABA was applied at $30 \mu \mathrm{M}$, a concentration shown to elicit submaximal responses in developing hypothalamic neurons (Chen et al., 1996). NPY-GFP+ neurons from P13-P15 mice showed membrane hyperpolarization
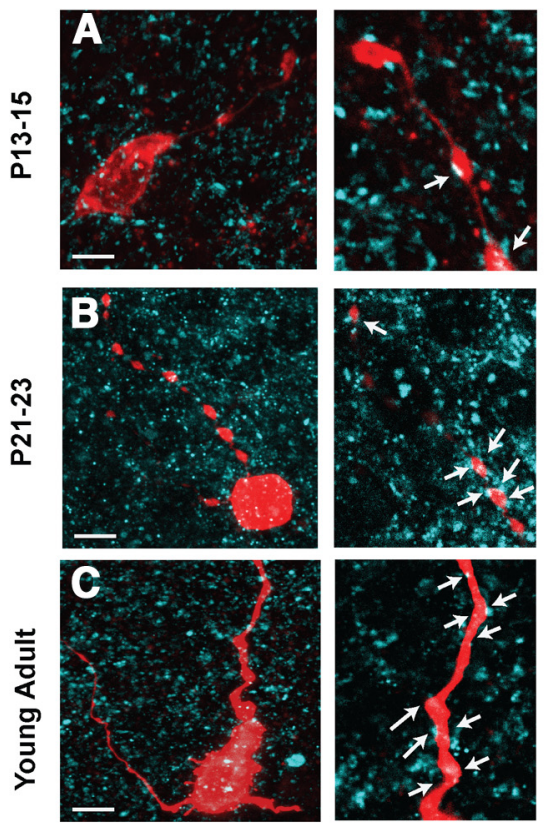

DMH Dil Implant
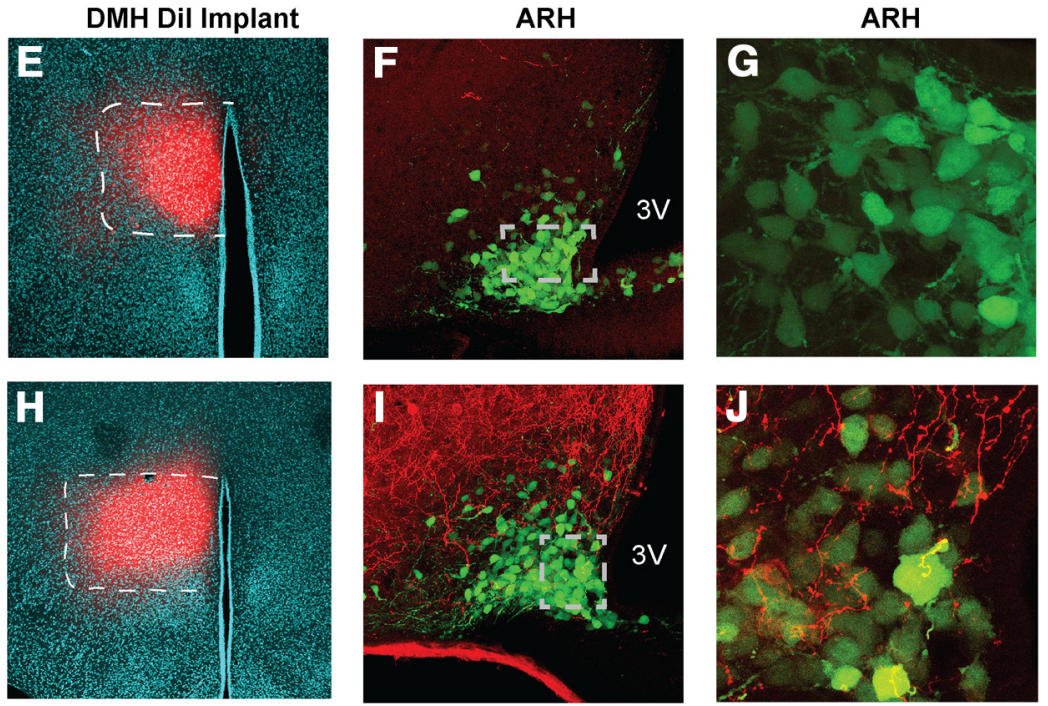

Figure 3. Age-associated changes in juxtaposed GABAergic terminals on NAG neurons and formation of projection pathways from the DMH to the ARH. A-C, Representative confocal images of NPY-GFP + somas and proximal process filled with biocytin (red) during electrophysiological recording and VGAT (cyan) immunoreactivity. Left, Maximum projection images. Right, Zoomed $1 \mu \mathrm{m}$ single optical slices in P13-P15 (A), P21-P23 (B), and young-adult mice (C). Arrows indicate juxtapositions (colocalization) suggesting possible synaptic contacts. Scale bar, $10 \mu \mathrm{m}$. D, Quantitative comparison of the number of VGAT synaptic boutons in close contact with biocytin-filled NAG proximal process ( $n=2-3$ optical sections per age, 31 animals). Results are shown as mean \pm SEM; ${ }^{* *} p<0.01$, by ANOVA, post hoc Tukey's test. $\boldsymbol{E}-\boldsymbol{J}$, Representative confocal images of Dil implants (red) and Dil-labeled fibers (red) in the DMH and ARH during the third week of postnatal development. $\boldsymbol{E}, \boldsymbol{H}$, Appearance and distribution of a Dil-implant (red) in the DMH of postnatal mice at P15 and P21; DAPI staining (cyan), 10X (white dashed lines indicate the borders of the DMH). Confocal images of the ARH taken at $40 \times(\boldsymbol{F}, \boldsymbol{I})$ and $63 \times$ with a digital zoom of two $(\boldsymbol{G}, \boldsymbol{J})$, showing the distribution of Dil-labeled (red) fibers and NPY-GFP + neurons (green) in two mice (P15 and P21). Gray dashed lines define the limits of the high-magnification $(63 \times)$ images. $3 V$, Third ventricle. in the presence of $30 \mu \mathrm{M}$ GABA. The magnitude of the hyperpolarization was $5 \pm 1 \mathrm{mV}$ in $\sim 77 \%$ of neurons tested (Fig. $4 A ; n=$ 13, 6 animals; $t_{(9)}=4.8, p<0.001$, paired $t$ test). At P21-P23, application of $30 \mu \mathrm{M}$ GABA continued to induce membrane hyperpolarization $\left(7.8 \pm 1.1 \mathrm{mV}\right.$; Fig. $4 A ; n=7,4$ animals; $t_{(6)}=$ $6.7, p=0.0005$, paired $t$ test). GABA inhibited $100 \%$ of NPYGFP+ neurons tested at P21-P23, which is similar to the levels observed in the adult. In young adults, $30 \mu \mathrm{M}$ GABA causes membrane hyperpolarization $(10.3 \pm 1.2 \mathrm{mV})$ in $100 \%$ of ARH NPY-GFP+ 
Table 1. Difference in density of VGAT and VGLUT2 synaptic boutons in the ARH during development

\begin{tabular}{llllll}
\hline Labeled synaptic boutons & P13-P15 & P21-P23 & Young adult (9-10 weeks) & Adult-lean (17-18 weeks) & Adult-DI0 (17-18 weeks) \\
\hline VGAT & $1 \pm 0.13$ & $1.18 \pm 0.2$ & $1.55 \pm 0.21^{a}$ & $0.95 \pm 0.1$ & $0.75 \pm 0.08^{a}$ \\
VGLUT2 & $1 \pm 0.1^{b}$ & $0.9 \pm 0.1^{c}$ & $0.85 \pm 0.12^{d}$ & $1.98 \pm 0.39^{b, c, d e}$ & $0.71 \pm 0.13^{e}$ \\
\hline
\end{tabular}

Results are shown as mean \pm SEM. The ratio of labeled synaptic boutons for VGAT or VGLUT2 in the ARH was calculated by normalizing all results to P13-P15 expression. Superscript letters indicate significant difference between groups by ANOVA, post hoc Tukey's test.

${ }^{a}$ Young adult versus adult-DIO.

${ }^{b}$ P13-P15 versus adult-lean.

CP21-P23 versus adult-lean.

${ }^{d}$ Young adult versus adult-lean.

${ }^{e}$ Adult-lean versus adult-DI0.
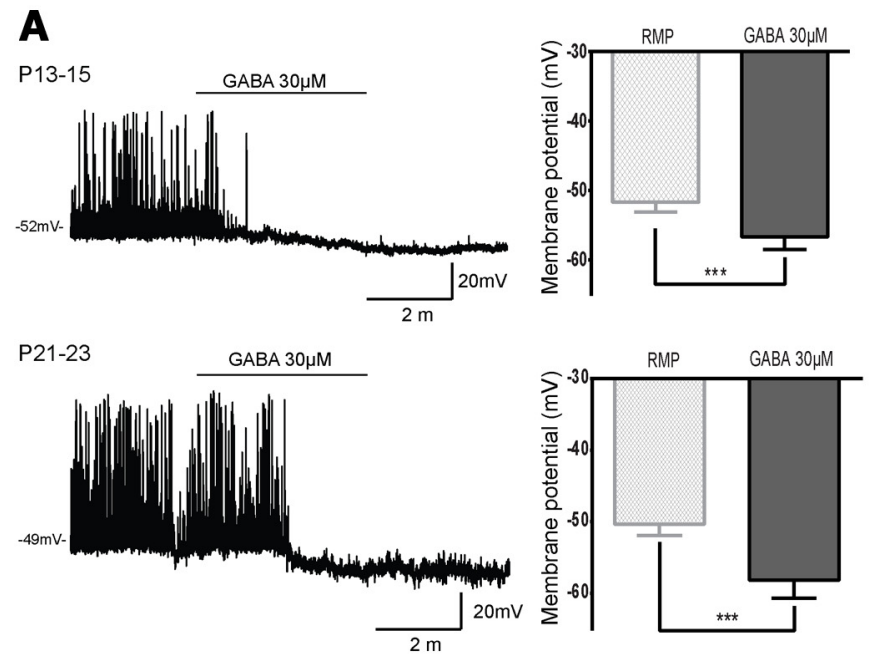

Young adult (9-10 weeks)

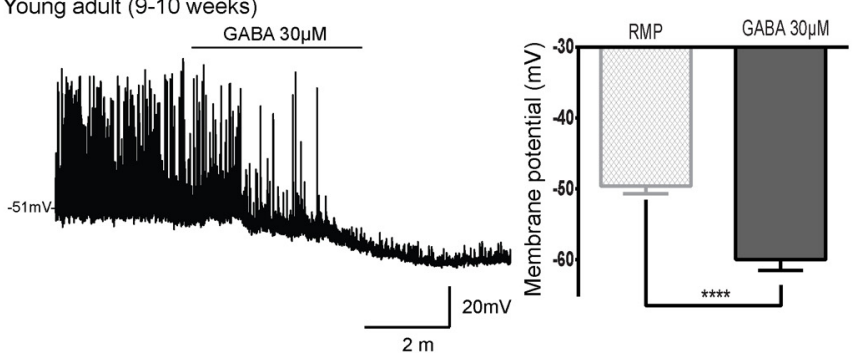

B

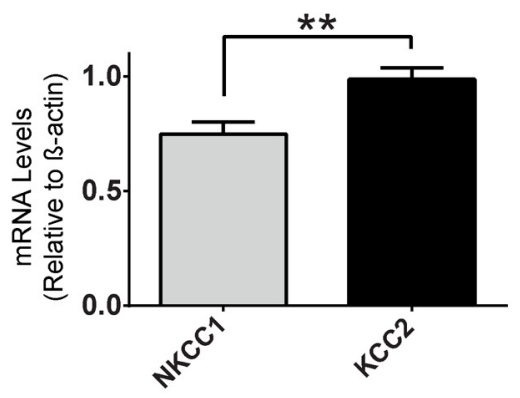

C

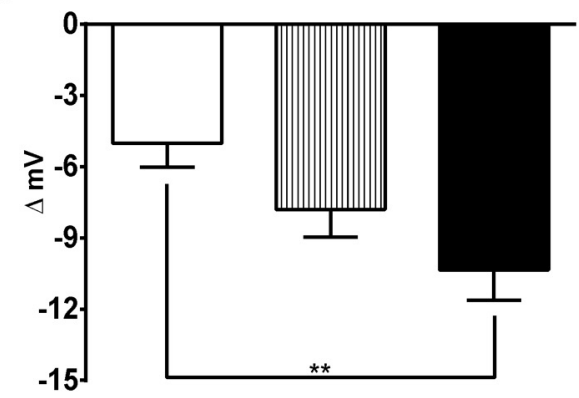

$\square \mathrm{P} 13-15$

IIII P21-23

Young Adult (9-10 weeks)

Figure 4. Development of inhibitory actions of GABA in NAG neurons. Representative traces of NAG neurons in current-clamp mode in the presence of GABA ( $30 \mu \mathrm{M}) . \boldsymbol{A}, \mathrm{GABA}$ leads to membrane hyperpolarization in NAG neurons at P13-P15 (10 of 13 neurons, 6 animals), P21-P23 (7 of 7 neurons, 4 animals), and young adult (10 of 10 neurons, 5 animals). Bar graphs show the magnitude of GABA responses in NAG neurons for each age. $B$, Quantification of mRNA levels for NKCC 1 and KCC2 by qPCR in ARH at P12-P13. ARH microdissected punches were pooled from two animals $(n=$ 10 animals). C, Quantitative comparison of the differences in GABA-mediated hyperpolarization in NAG neurons from P13 through 10 weeks of age. Results are shown as mean \pm SEM; ** $p<0.01$, ${ }^{* * *} p<0.001,{ }^{* * * *} p<0.0001$ by unpaired, paired $t$ test or ANOVA, post hoc Bonferroni correction. RMP, Resting membrane potential.

neurons (Fig. $4 A ; n=10,5$ animals; $t_{(9)}=8, p<0.0001$, paired $t$ test). Furthermore, quantitative analysis revealed that GABAmediated hyperpolarization of NAG neurons increased with age (Fig. $4 C ; n=30,15$ animals; ANOVA with post hoc Bonferroni correction shows significant differences in GABA responses: $F_{(2,24)}$ $=5.7, p=0.0089 ; \mathrm{P} 13-\mathrm{P} 15$ vs young adult: $\left.t_{(24)}=3.4, p<0.01\right)$.

GABA decreases neuronal activity through both ligand-gated $\mathrm{GABA}_{\mathrm{A}}$ receptor and the $\mathrm{G}$-protein-coupled $\mathrm{GABA}_{\mathrm{B}}$ receptor in the adult nervous system (Obrietan and van den Pol, 1998). To investigate whether there is a developmental difference in the function of $\mathrm{GABA}_{\mathrm{B}}$ receptors, we performed electrophysiological

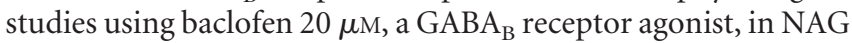
neurons at P13-P15 and young adult (9-10 weeks). We found that baclofen leads to membrane hyperpolarization in NAG neurons in both pups and adults (Fig. 5A). The magnitude of baclofen-mediated hyperpolarization was $-8.7 \pm 1.6 \mathrm{mV}$ (P13P15; $n=6,4$ animals; $t_{(5)}=5.2, p<0.05$, paired $t$ test) and
$-11.1 \pm 3 \mathrm{mV}$ (young adults; $n=4,4$ animals; $t_{(3)}=3.6, p<$ 0.05 , paired $t$ test). However, there were no significant differences in baclofen responses between pups and adults (Fig. $5 B ; p>$ $0.05)$. Together, our results indicate that after P13, GABA actions in orexigenic NAG neurons are inhibitory.

\section{Development of excitatory synaptic transmission on NAG} neurons in the ARH

Recent studies in mice have shown that fasting and ghrelin can activate NAG neurons by presynaptic release of glutamate to initiate food-seeking behavior in adults (Yang et al., 2011; Liu et al., 2012). Because high-energy intake is necessary to fuel rapid growth in pups, we wanted to investigate the ontogeny of spontaneous EPSCs (sEPSCs) in ARH NPY neurons. NPY-GFP+ neurons from P13-P15, P21-P23, and young adult (9-10 weeks) mice were held at $-60 \mathrm{mV}$ under voltage-clamp mode. Bicuculline $(5 \mu \mathrm{M}), \mathrm{a} \mathrm{GABA}_{\mathrm{A}}$ receptor antagonist, was used to isolate 
A

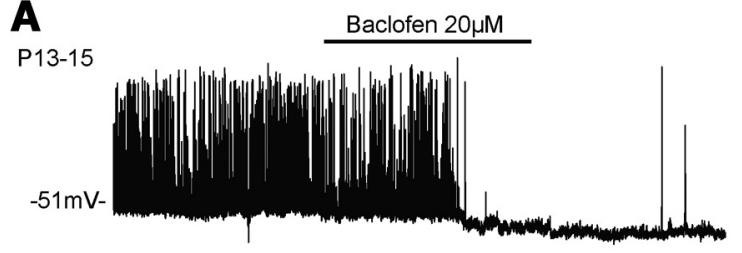

Young adult (9-10 weeks)

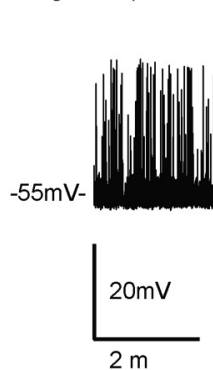

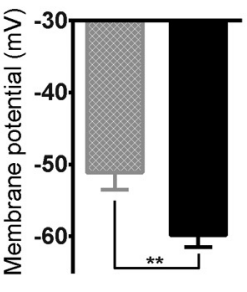

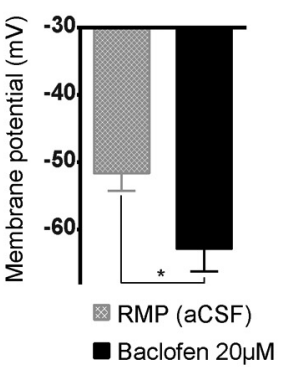

B

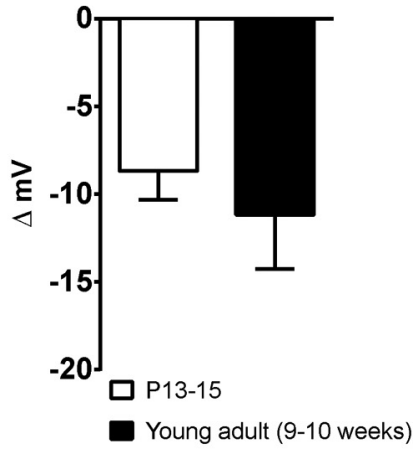

Figure 5. Functional actions of GABA ${ }_{B}$ receptor in NAG neurons during postnatal development. Representative traces of NAG neurons in current-clamp mode in the presence of baclofen (20 $\mu \mathrm{m}$ ). $A$, Baclofen causes membrane hyperpolarization in NAG neurons at P13-P15 (6 cells from 4 animals) and young adult (4 cells from 4 animals). Bar graphs show the effects of baclofen in the membrane potential of NAG neurons. $\boldsymbol{B}$, Bar graphs show the magnitude of baclofen-mediated hyperpolarization in pups and adults. Results are shown as mean \pm SEM; ${ }^{*} p<0.05,{ }^{* *} p<0.01$ by paired $t$ test. RMP, Resting membrane potential.

sEPSCs (Fig. 6A). Through the end of the second week of age (P13-P15), we observed that the number of excitatory currents was relatively abundant with a sEPSC frequency of $0.52 \pm 0.08$ $\mathrm{Hz}$ (Fig. $6 A, C ; n=7,6$ animals). After P21, when pups transition to autonomic feeding, there was no difference in the frequency of sEPSCs in NAG neurons $(0.61 \pm 0.1 \mathrm{~Hz}$; Fig. $5 A, B ; n=7,5$ animals; $p>0.05$, ANOVA). In young adults, the number of sEPSCs stayed consistent and sEPSC frequency was $0.69 \pm 0.1 \mathrm{~Hz}$ (Fig. $6 A, B ; n=11,6$ animals; $p>0.05$ ). Similar frequencies of EPSCs onto NAG neurons were observed in the presence of TTX in all age groups (Fig. $6 C ; n=25,17$ animals; $p>0.05$, ANOVA). There was no difference in amplitude of sEPSCs and mEPSCs between ages in these experiments (data not shown).

To further characterize the correlation between the number of excitatory synaptic inputs and age in NAG neurons, we used postrecording immunohistochemistry for VGLUT2 in biocytinlabeled NPY-GFP+ neurons. We measured the area and circularity of VGLUT2-labeled synaptic boutons. We found that the size of VGLUT2 vesicles remain similar from postnatal development through adulthood (Fig. $1 B ; n=6-8$ optical sections, 9 animals; $p>0.05$ ). The number of excitatory synapses onto the first $50 \mu \mathrm{M}$ of proximal processes of NAG neurons was analyzed. In general, NAG neurons had fewer VGLUT2 synapses in filled processes at P13-P15 compared with older animals (Fig. 6D, G; $n=2-3$ optical sections, 6 animals). By P21, the number of VGLUT2 synaptic boutons closely apposed to the filled processes increased $\sim 57 \%$, but this difference did not reach significance (Fig. $6 E, G ; n=2-3$ optical sections, 5 animals; $p>0.05$ ). In young adult, the amount of VGLUT2 appositions in proximal processes of NAG neurons remained similar to the P21-P23 age (Fig. $6 F, G ; n=2-3$ optical sections, 6 animals). Furthermore, the overall density of VGLUT2-labeled synaptic boutons in the ARH was similar throughout development (Table 1). Our results demonstrate that NAG neurons receive the same amount of glutamatergic inputs from postnatal development to adulthood.

Age and diet-associated changes in synaptic distribution in NAG neurons

Because we observed differences in synaptic transmission in NAG neurons throughout development, we next examined the effects of diet and aging on the distribution of synaptic inputs in NAG neurons. We recorded sIPSCs and performed postrecording immunohistochemistry for VGAT in 17- to 18-week-old lean (denoted as adult-lean) and DIO (denoted as adult-DIO) mice. We found that the frequency of sIPSCs was significantly decreased in NAG neurons from adult-DIO mice compared with NAG neurons from age-matched lean mice (Fig. $7 A ; n=20,11$ animals; $t_{(17)}=2.4, p=0.02$, unpaired $t$ test). Surprisingly, we observed that IPSC frequency in NAG neurons decreases with age from $0.69 \pm 0.08 \mathrm{~Hz}$ in young adult (9- to 10 -weeks-old) to $0.43 \pm 0.03$ $\mathrm{Hz}$ in adult-lean mice (17-18 weeks old; Figs. $2 C, 6 A ; n=15,8$ animals; $t_{(13)}=2.9, p=0.01$, unpaired $t$ test). To determine the contribution of mIPSCs at this age, we used TTX $(1 \mu \mathrm{M})$ to block spontaneously occurring postsynaptic currents. TTX had a minor (but not significant) effect on the average number of mIPSCs in adult-lean and adult-DIO (Fig. $7 A ; n=12,7$ animals; $p>$ $0.05)$. In these experiments, we detected differences in IPSC frequency between DIO and age-matched lean mice; however, there was no difference in the amplitude of IPSCs between these two groups (data not shown). Furthermore, we observed a reduction in the number of GABAergic terminals per $1 \mu \mathrm{M}$ of proximal processes in NAG neurons between adult-lean and age-matched adult-DIO mice (Fig. 7C-E; $n=2-3$ optical sections, 7 animals; $t_{(27)}=2.3, p=0.02$, unpaired $t$ test). Similar changes in the density of VGAT-labeled synaptic boutons in the ARH were observed, but the findings were not significant (Table 1). We did find significant differences in the number of VGAT-labeled synaptic boutons between adult-DIO and young adult (Table 1; 31 animals, ANOVA with post hoc Tukey's shows significant changes by age in the density of VGAT-labeled boutons in the $\left.\mathrm{ARH} ; F_{(4,50)}=3.6, p<0.05 ; q_{(50)}=4.9, p<0.01\right)$. Our results revealed that GABAergic tone onto NAG neurons is decreased by age and obesity.

To explore whether excitatory synapses onto NAG neurons are reorganized by diet and age, we recorded EPSCs and performed postrecording immunohistochemistry for VGLUT2 in adult-lean and adult-DIO mice. We found that sEPSC frequency is lower in NAG neurons from DIO mice than age-matched lean mice (Fig. $7 B ; n=19,12$ animals; $t_{(17)}=2.5, p=0.02$, unpaired $t$ test). We also detected a trend toward lower amplitude in EPSCs 
A

P13-15

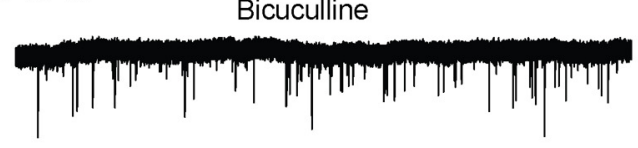

P21-23

Bicuculline

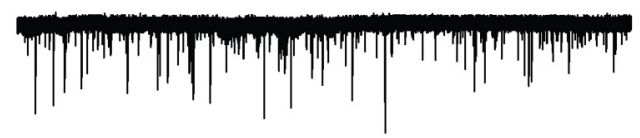

Young adult (9-10 weeks)

Bicuculline

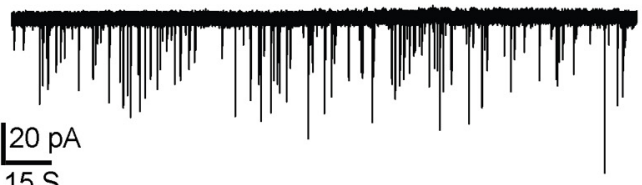

B

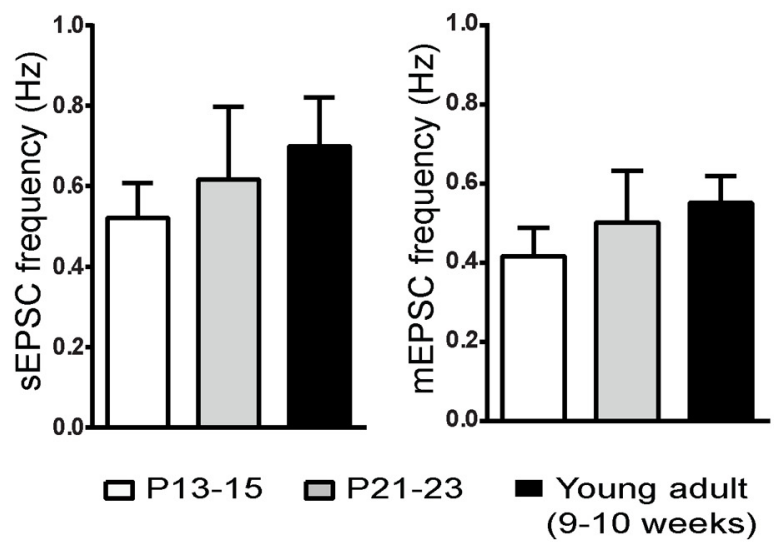

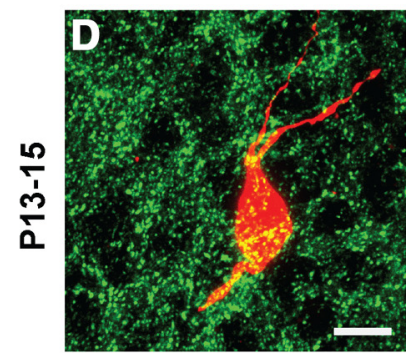
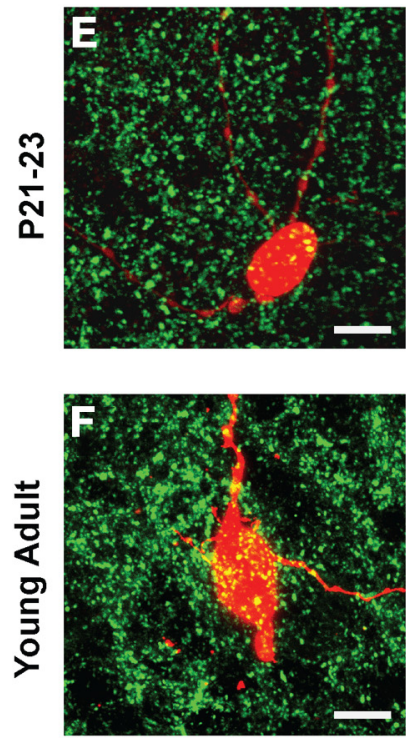
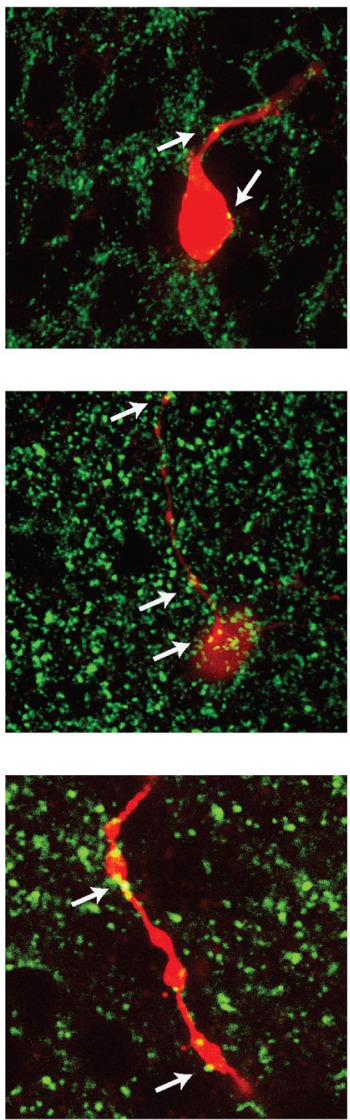

G

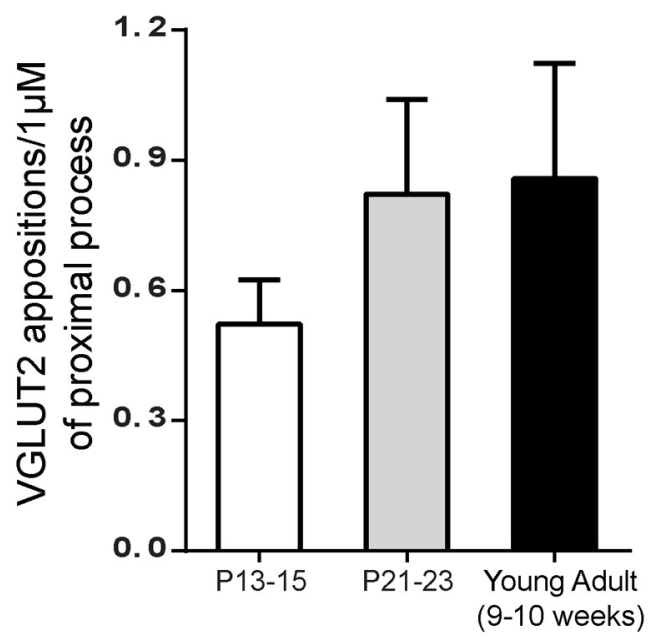

Figure 6. Characterization of EPSCS and juxtaposed glutamatergic terminals in NAG neurons from the preweaning period throughout adulthood. $A$, Representative traces for $5 E P S C S$ in NAG neurons at P13-P15 (7 cells, 6 animals), P21-P23 (7 cells, 5 animals), and young adult (11 cells, 6 animals). Bicuculline (5 $\mu$ m) was used to blocked GABA $A_{A}$ receptors during the recordings. B, C, Bar graphs show frequency for sEPSCs and mEPSCs respectively. $\boldsymbol{D}-\boldsymbol{F}$, Representative confocal images of combined biocytin-filled-NAG neurons (red) and VGLUT2 (green) immunoreactivity for P13-P15 (D), P21-P23 (E), and young adult $(\boldsymbol{F})$. Maximal projection image (left). Zoomed $1 \mu \mathrm{m}$ single optical slices of proximal process (right). Arrows indicate juxtaposed terminals. Scale bar, $10 \mu \mathrm{M}$. $\mathbf{G}$, Bar graphs show the quantitative comparison of the number of VGLUT2 synaptic boutons in close contact with biocytin-filled NAG proximal process ( $n=2-3$ optical sections per age, 23 animals). Results are shown as mean \pm SEM.

of NAG neurons from DIO mice, however, this difference was not significant (data not shown, $p>0.05$ ). Similar results were observed with mEPSCs (Fig. $7 B ; n=18,12$ animals $p>0.05$ ). Although, we detected that EPSC frequency tended to be higher in NAG from 17- to 18-week-old lean mice $(0.9 \pm 0.2 \mathrm{~Hz})$ than young adults $(0.69 \pm 0.1 \mathrm{~Hz})$, these changes were not significant $(p>0.05)$. In agreement with our electrophysiological studies, DIO mice had a reduced number of juxtaposed glutamatergic terminals on NAG neurons compared with age-matched lean mice (Fig. $7 F-H ; n=2-3$ optical sections, 7 animals; $t_{(19)}=2.2$, $p=0.03$, unpaired $t$ test). Others have reported similar findings in the ARH of adult DIO mice (Horvath et al., 2010). Further- 
A Adult-Lean (17-18 weeks)

APV/CNQX

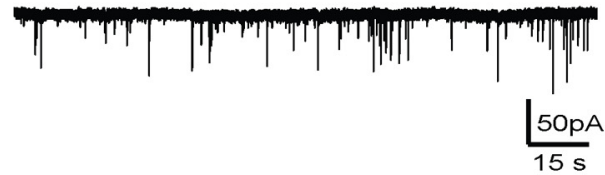

Adult-DIO (17-18 weeks)
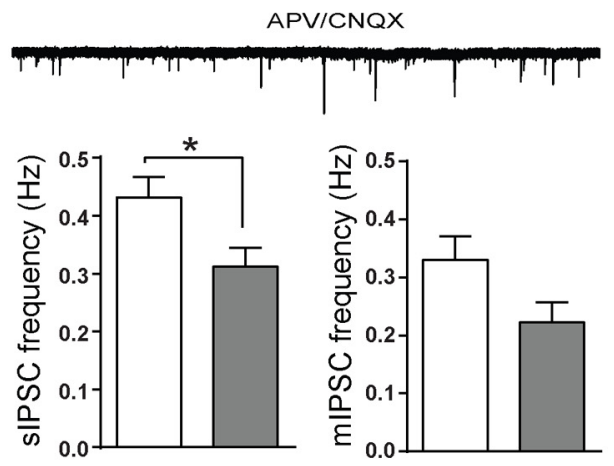

$\square$ Adult-Lean (17-18 weeks)
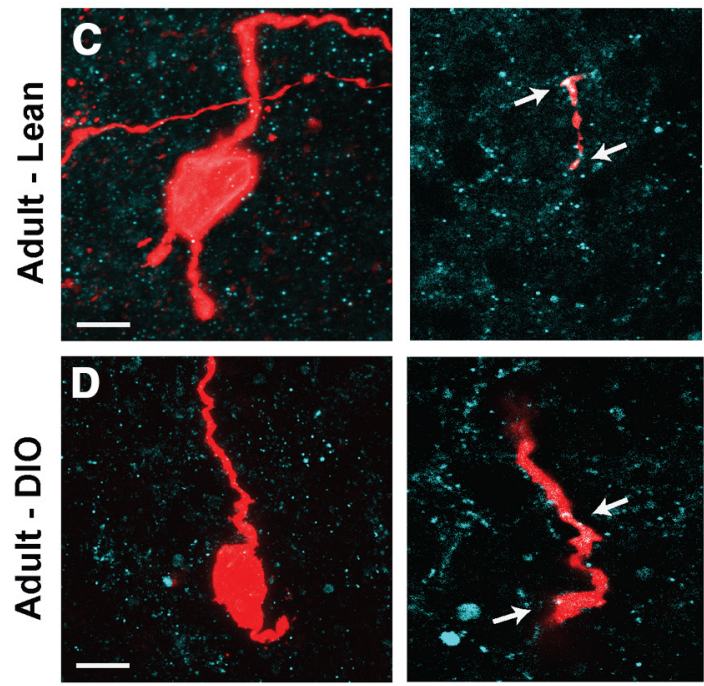

E

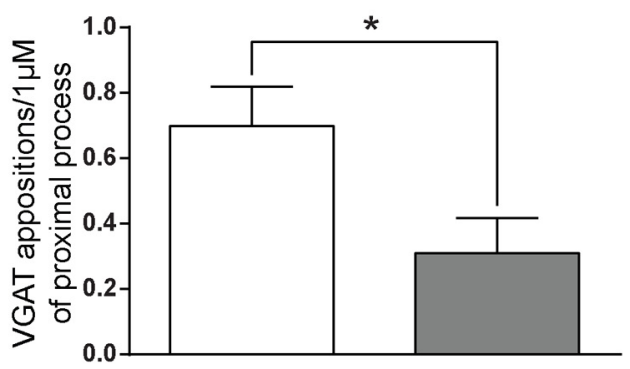

B Adult-Lean (17-18 weeks)

Bicuculline

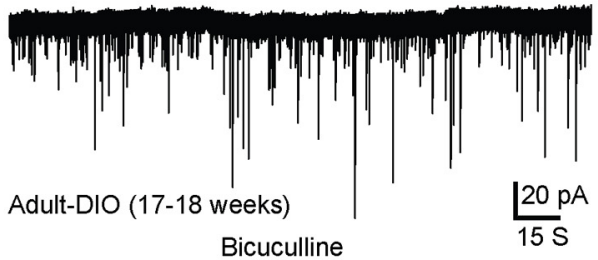

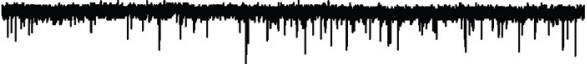
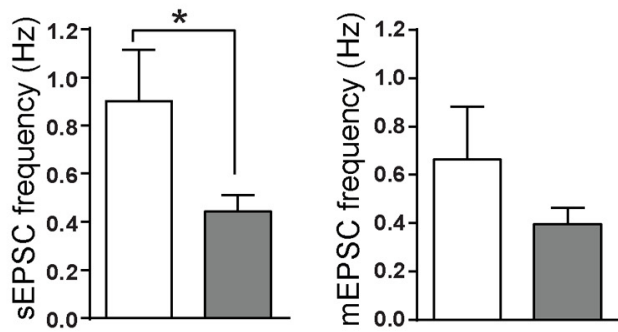

$\square$ Adult-DIO (17-18 weeks)
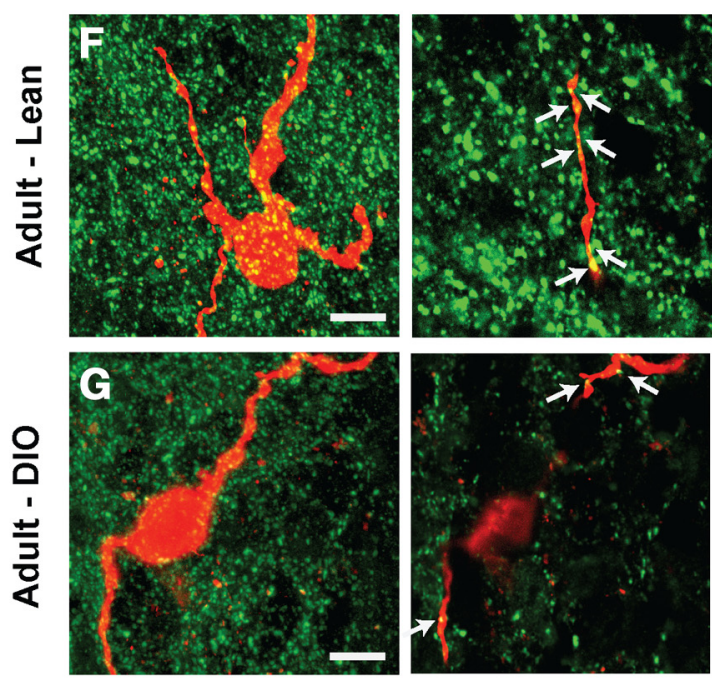

H

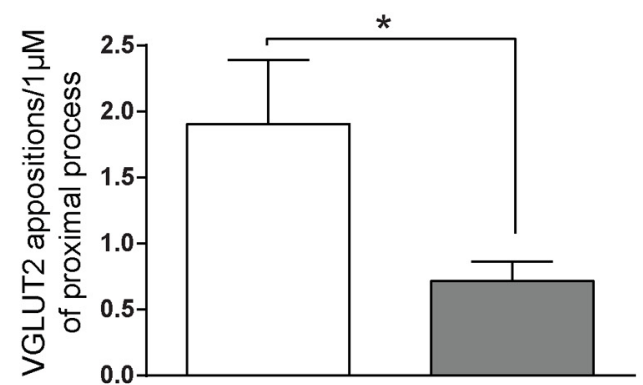

Figure 7. Changes in synaptic input organization in DI0-NAG neurons. Representative traces of sIPSCS (A) and sEPSCS (B) from ARH-NPY-GFP+ in adult-lean (17-18 weeks old; 15 cells, 9 animals) and adult-DI0 (17-18 weeks old; 24 cells, 14 animals) mice. APV $(50 \mu \mathrm{M}) / C N Q X(10 \mu \mathrm{M})$ were used to block glutamate receptors (left). Bicuculline (5 $\mu \mathrm{M})$ was applied to block GABA receptors (right). Bar graphs show changes in the frequency of SIPSC and mIPSC $(\boldsymbol{A})$, and sEPSC and mEPSC (B) in lean versus DI0 mice. Representative confocal images of combined biocytin-filled NAG neurons (red) and immunoreactivity for vesicular transporters: VGAT (cyan) and VGLUT2 (green) in adult-lean (C, $\boldsymbol{F}$ ) and adult-DI0 (D, G). Left, Maximal projection image. Right, Zoomed $1 \mu \mathrm{M}$ single optical slices of proximal process. Arrows indicate juxtaposed terminals. Scale bar, $10 \mu \mathrm{m}$. E, Bar graph show differences in synaptic boutons in close contact with NAG proximal process for VGAT $(\boldsymbol{E})$ and VGLUT2 $(\boldsymbol{H})$ in lean and DI0 mice $\left(n=2-3\right.$ optical sections per age, 11 animals). Results are shown as mean \pm SEM; ${ }^{*} p<0.05$ by unpaired $t$ test.

more, we found a greater density of VGLUT2 synaptic boutons in adult-lean mice than at any other age (Table 1; 23 animals, ANOVA with post hoc Bonferroni's correction shows significant changes by age in the density of VGLUT2-labeled boutons in the
ARH: $F_{(4,36)}=5.9, p=0.00009$; P13-P15 vs adult-lean: $t_{(36)}=$ $3.2, p<0.05$; P21-P23 vs adult-lean: $t_{(36)}=3.6, p<0.01$; young adult vs adult-lean: $t_{(36)}=3.9, p<0.01$; adult-lean vs adult-DIO: $\left.t_{(36)}=4.4, p<0.001\right)$. Together, our findings demonstrate that 
chronic consumption of HFD for 12 weeks decreases GABAergic and glutamatergic tone in NAG neurons.

\section{Discussion}

In the present study, we examined the number of excitatory and inhibitory synapses and postsynaptic currents on NAG neurons during the first 5 months of life. We found that GABAergic tone onto NAG neurons is low at P13, with a rapid increase peaking at 9 weeks of age, and a return to levels observed in the weaning period by 17 weeks of age. In contrast, we observed that glutamatergic inputs onto NAG neurons remain relatively steady throughout development and adulthood. Strikingly, we detected that there was a switch in the organization of synaptic inputs in the ARH by 17 weeks of age and adult NAG neurons received almost twice the amount of glutamatergic synapses than GABAergic. Furthermore, we reported that DIO reduces synaptic transmission onto NAG neurons.

The physiological role of GABA and glutamate with regard to energy homeostasis during development has been overlooked. Here, we demonstrate that presynaptic release of GABA in the ARH is low during the first 2 weeks of development. Because GABA actions rely on presynaptic $\mathrm{GABA}_{\mathrm{A}}$ receptors to trigger IPSCs, our results suggest that phasic GABA inhibition between neurons in the ARH is not well established at this age (Cherubini, 2012). The low number of inhibitory inputs in ARH neurons, at this age, may be important to stimulate neuronal projections to feeding centers located outside of the hypothalamus. Indeed, projections from ARH neurons to the parabrachial nucleus are not completely developed until P21 (Nilsson et al., 2005; Atasoy et al., 2012). A previous study has suggested that the GABA signaling is excitatory in isolated hypothalamic neurons during the first week of postnatal development (Chen et al., 1996). However, we show in brain slices that $\mathrm{GABA}_{\mathrm{A}}$ and $\mathrm{GABA}_{\mathrm{B}}$ actions in NAG neurons are inhibitory after P13. Although NAG neurons exhibited adult-like characteristics in GABA signaling at P13, future studies are needed to investigate the expression of $\mathrm{KCC} 2$, NKCC1, and composition of GABA receptors in the ARH throughout the animal's life. In contrast, our results showed that presynaptic release of glutamate is relatively abundant at the end of the second week of development. The number of excitatory synapses at P13 is similar to levels observed in the adult. Because high-energy intake is necessary for rapid growth, it is possible to speculate that activation of NAG neurons by glutamate release from the presynaptic terminals could lead to orexigenic actions in pups. Consistent with this idea, previous studies in adult mice have shown that fasting and the orexigenic hormone ghrelin increased excitatory inputs onto NAG neurons to create adaptive responses that restore the body's fuel levels and energy balance (Pinto et al., 2004; Takahashi and Cone, 2005; Yang et al., 2011; Liu et al., 2012). If this is the case during postnatal development, ghrelin may act through NAG neurons to provide a potent orexigenic stimulus. Indeed, a previous study has shown that exogenous ghrelin increases NPY mRNA expression as early as P10 (Steculorum and Bouret, 2011). More studies are needed to characterize the role of synaptic transmission in the regulation of food intake during postnatal development.

A previous report has shown that synaptic formation is an active process in the ARH of rats throughout the first $45 \mathrm{~d}$ of life (Matsumoto and Arai, 1976). Our results revealed that a similar process occurs in mice. However, we only found developmental differences in inhibitory synapses in the ARH of mice, suggesting that excitatory synapses onto NAG neurons are formed before the initiation of solid food consumption. Furthermore, Horvath et al., (2010) has previously characterized excitatory and inhibitory synapses onto NAG neurons between 4 and 8 weeks of age (Pinto et al., 2004). After P30, NAG neurons exhibited similar synaptic distribution to the young adult (9-10 weeks). Our focus in this work was to characterize synaptic distribution in NAG neurons at two critical developmental periods: (1) initiation of solid food intake (P13-P15) and (2) development of autonomic feeding (P21-P23). However, it is possible to speculate that synaptic distribution in NAG neurons only transitions to the adult phenotype after hypothalamic circuits are completely developed at the end of the fourth week (Grove et al., 2005). Supporting this idea, previous studies have established that synaptic inputs progress to the adult phenotype throughout the fourth and fifth week of life (Melnick et al., 2007; Ehrlich et al., 2013).

It is established that the DMH contains both glutamatergic and GABAergic neurons (Vong et al., 2011). A recent study using optogenetics has demonstrated that DMH neurons are upstream regulators of NAG neurons and may be involved in control of food intake (Krashes et al., 2014). Given this, we hypothesized that the ARH must receive strong neuronal inputs from DMH. Indeed, our experiments using DiI tracer showed that the DMH sent afferent projections to ARH. These neuronal projections from DMH to ARH begin to develop during the third week of life. Because of technical limitations due to overfixation of our tissue, we could not identify the phenotype of these axonal projections. Nevertheless, our immunohistochemical studies suggest that most of these neuronal projections are GABAergic because we detected a greater increase in the number of juxtaposed VGAT contacts onto NAG from P13-P15 to P21-P23. Although changes in VGLUT2 contacts onto NAG neurons were minor between these ages, we cannot rule out the possibility that glutamatergic inputs are developed after P23. Future studies are needed to determine the phenotype of these afferent projections from the DMH to the ARH, as well as the characterization of afferent inputs from other brain areas, such as the brainstem.

Changes in the balance between the firing rates of $\mathrm{ARH}$ neurons in response to hormonal environment and nutrients are considered important for feeding behavior in the adult rodent (Zeltser et al., 2012). For instance, leptin, a fat-derived hormone, is associated with rapid synaptic reorganization. Exogenous leptin leads to an increase in inhibitory synapses in young NAG neurons. Surprisingly, old NAG neurons (17 weeks old) exhibited similar synaptic distribution as leptin deficient (ob/ob) mice (Pinto et al., 2004). This could be explained by changes in adiposity and leptin levels in older animals. (Ahrén et al., 1997; Wolden-Hanson et al., 1999; Newton et al., 2013). More studies are needed to investigate this. In this study, we hypothesized that consumption of a HFD for 12 weeks will increase GABAergic tone and simultaneously decrease in glutamatergic inputs in NAG neurons. Unexpectedly, we found that inhibitory synapses onto NAG neurons were reduced in age-matched lean (17-18 weeks old) mice, whereas the number of excitatory synapses onto NAG neurons remains the same. Our findings suggest that changes in synaptic distribution of NAG neurons might play a role in body weight increase throughout adulthood. Consistent with this idea, removal of glutamatergic ionotropic receptors (NMDARs) from NAG neurons leads to a reduction in body fat and weight (Liu et al., 2012). Furthermore, others have shown an age-related increase in the activity and innervation of NAG neurons (Newton et al., 2013). Future studies are 
needed to characterize the role of synaptic plasticity in ageassociated bodyweight increase.

After 12 weeks on HFD, we observed a reduction in synaptic transmission onto NAG neurons in DIO mice (17-18 weeks old). The fact that synaptic input organization of NAG neurons was restructured during DIO supports the idea of hypothalamic inflammation and reactive gliosis (Horvath et al., 2010; Koch and Horvath, 2014). Although, NAG neurons from DIO mice exhibited a reduction in glutamatergic and GABAergic tone compared with NAG neurons from age-matched lean littermates, there were no significant changes in excitatory versus inhibitory balance in NAG neurons of DIO mice at this age. A previous study showed that only excitatory synapses were reduced in NAG neurons in DIO mice after 20 weeks on HFD (Horvath et al., 2010). It is possible to speculate that these differences are due to a reduction in GABAergic tone onto NAG neurons in lean mice that may occur as animals continue to age. Conversely, changes in glutamatergic inputs in obese neurons could be due to the following possibilities: (1) a homeostatic response to the decrease in GABAergic tone. (2) Alterations in neurotransmitter release by neuronal injury of microglia and astroglia in the ARH (Grayson et al., 2010; Fuente-Martín et al., 2012; Thaler et al., 2012). In this study, there were differences in the appearance of VGAT labeling between 17 and 18 weeks (lean and DIO) relative to younger ages. In contrast, these age-associated differences were not observed with VGLUT2 labeling. Furthermore, our electrophysiological results for IPSCs correlate well with the VGAT labeling observed across all ages.

In conclusion, we show evidence that age plays a role in the wiring of NAG neurons. Because activation of NAG neurons leads to increased feeding, decreased energy expenditure, and enlarged fat stores (Aponte et al., 2011; Krashes et al., 2011; Krashes et al., 2013), it is possible that age-dependent changes in synaptic distribution of NAG neurons may contribute to the control of energy balance. However, further studies are needed to characterize the relative contribution of central integration of afferent signals by NAG neurons in energy homeostasis.

\section{References}

Ahrén B, Månsson S, Gingerich RL, Havel PJ (1997) Regulation of plasma leptin in mice: influence of age, high-fat diet, and fasting. Am J Physiol 273:R113-R120. Medline

Aponte Y, Atasoy D, Sternson SM (2011) AGRP neurons are sufficient to orchestrate feeding behavior rapidly and without training. Nat Neurosci 14:351-355. CrossRef Medline

Atasoy D, Betley JN, Su HH, Sternson SM (2012) Deconstruction of a neural circuit for hunger. Nature 488:172-177. CrossRef Medline

Chen G, Trombley PQ, van den Pol AN (1996) Excitatory actions of GABA in developing rat hypothalamic neurones. J Physiol 494:451-464. CrossRef Medline

Cherubini E (2012) Phasic GABAA-mediated inhibition. In: Jasper's Basic Mechanisms of the Epilepsies, Ed 4 (Noebels JL, Avoli M, Rogawski MA, Olsen RW, Delgado-Escueta AV, eds). Bethesda, MD: Oxford UP.

Ehrlich DE, Ryan SJ, Hazra R, Guo JD, Rainnie DG (2013) Postnatal maturation of GABAergic transmission in the rat basolateral amygdala. J Neurophysiol 110:926-941. CrossRef Medline

Fuente-Martín E, García-Cáceres C, Granado M, de Ceballos ML, SánchezGarrido MÁ, Sarman B, Liu ZW, Dietrich MO, Tena-Sempere M, Argente-Arizón P, Díaz F, Argente J, Horvath TL, Chowen JA (2012) Leptin regulates glutamate and glucose transporters in hypothalamic astrocytes. J Clin Invest 122:3900-3913. CrossRef Medline

Gao XB, van den Pol AN (2001) GABA, not glutamate, a primary transmitter driving action potentials in developing hypothalamic neurons. J Neurophysiol 85:425-434. Medline

Grayson BE, Levasseur PR, Williams SM, Smith MS, Marks DL, Grove KL (2010) Changes in melanocortin expression and inflammatory pathways in fetal offspring of nonhuman primates fed a high-fat diet. Endocrinology 151:1622-1632. CrossRef Medline

Gropp E, Shanabrough M, Borok E, Xu AW, Janoschek R, Buch T, Plum L, Balthasar N, Hampel B, Waisman A, Barsh GS, Horvath TL, Brüning JC (2005) Agouti-related peptide-expressing neurons are mandatory for feeding. Nat Neurosci 8:1289-1291. CrossRef Medline

Grove KL, Grayson BE, Glavas MM, Xiao XQ, Smith MS (2005) Development of metabolic systems. Physiol Behav 86:646-660. CrossRef Medline

Horvath TL, Sarman B, García-Cáceres C, Enriori PJ, Sotonyi P, Shanabrough M, Borok E, Argente J, Chowen JA, Perez-Tilve D, Pfluger PT, Brönneke HS, Levin BE, Diano S, Cowley MA, Tschöp MH (2010) Synaptic input organization of the melanocortin system predicts dietinduced hypothalamic reactive gliosis and obesity. Proc Natl Acad Sci U S A 107:14875-14880. CrossRef Medline

Jobst EE, Enriori PJ, Cowley MA (2004) The electrophysiology of feeding circuits. Trends Endocrinol Metab 15:488-499. CrossRef Medline

Koch M, Horvath TL (2014) Molecular and cellular regulation of hypothalamic melanocortin neurons controlling food intake and energy metabolism. Mol Psychiatry 19:752-761. CrossRef Medline

Krashes MJ, Koda S, Ye C, Rogan SC, Adams AC, Cusher DS, Maratos-Flier E, Roth BL, Lowell BB (2011) Rapid, reversible activation of AgRP neurons drives feeding behavior in mice. J Clin Invest 121:1424-1428. CrossRef Medline

Krashes MJ, Shah BP, Koda S, Lowell BB (2013) Rapid versus delayed stimulation of feeding by the endogenously released AgRP neuron mediators GABA, NPY, and AgRP. Cell Metab 18:588-595. CrossRef Medline

Krashes MJ, Shah BP, Madara JC, Olson DP, Strochlic DE, Garfield AS, Vong L, Pei H, Watabe-Uchida M, Uchida N, Liberles SD, Lowell BB (2014) An excitatory paraventricular nucleus to AgRP neuron circuit that drives hunger. Nature 507:238-242. CrossRef Medline

Lee SJ, Verma S, Simonds SE, Kirigiti MA, Kievit P, Lindsley SR, Loche A, Smith MS, Cowley MA, Grove KL (2013) Leptin stimulates neuropeptide $\mathrm{Y}$ and cocaine amphetamine-regulated transcript coexpressing neuronal activity in the dorsomedial hypothalamus in diet-induced obese mice. J Neurosci 33:15306-15317. CrossRef Medline

Liu T, Kong D, Shah BP, Ye C, Koda S, Saunders A, Ding JB, Yang Z, Sabatini BL, Lowell BB (2012) Fasting activation of AgRP neurons requires NMDA receptors and involves spinogenesis and increased excitatory tone. Neuron 73:511-522. CrossRef Medline

Luquet S, Perez FA, Hnasko TS, Palmiter RD (2005) NPY/AgRP neurons are essential for feeding in adult mice but can be ablated in neonates. Science 310:683-685. CrossRef Medline

Matsumoto A, Arai Y (1976) Developmental changes in synaptic formation in the hypothalamic arcuate nucleus of female rats. Cell Tissue Res 169: 143-156. Medline

Melnick I, Pronchuk N, Cowley MA, Grove KL, Colmers WF (2007) Developmental switch in neuropeptide $\mathrm{Y}$ and melanocortin effects in the paraventricular nucleus of the hypothalamus. Neuron 56:1103-1115. CrossRef Medline

Newton AJ, Hess S, Paeger L, Vogt MC, Fleming Lascano J, Nillni EA, Brüning JC, Kloppenburg P, Xu AW (2013) AgRP innervation onto POMC neurons increases with age and is accelerated with chronic high-fat feeding in male mice. Endocrinology 154:172-183. CrossRef Medline

Nilsson I, Johansen JE, Schalling M, Hökfelt T, Fetissov SO (2005) Maturation of the hypothalamic arcuate agouti-related protein system during postnatal development in the mouse. Brain Res Dev Brain Res 155:147154. CrossRef Medline

Obrietan K, van den Pol AN (1998) GABAB receptor-mediated inhibition of GABAA receptor calcium elevations in developing hypothalamic neurons. J Neurophysiol 79:1360-1370. Medline

Pinto S, Roseberry AG, Liu H, Diano S, Shanabrough M, Cai X, Friedman JM, Horvath TL (2004) Rapid rewiring of arcuate nucleus feeding circuits by leptin. Science 304:110-115. CrossRef Medline

Qiu J, Fang Y, Rønnekleiv OK, Kelly MJ (2010) Leptin excites proopiomelanocortin neurons via activation of TRPC channels. J Neurosci 30:1560 1565. CrossRef Medline

Steculorum SM, Bouret SG (2011) Developmental effects of ghrelin. Peptides 32:2362-2366. CrossRef Medline

Sun C, Zhang L, Chen G (2013) An unexpected role of neuroligin-2 in regulating KCC2 and GABA functional switch. Mol Brain 6:23. CrossRef Medline 
Swithers SE (2003) Do metabolic signals stimulate intake in rat pups? Physiol Behav 79:71-78. CrossRef Medline

Takahashi KA, Cone RD (2005) Fasting induces a large, leptin-dependent increase in the intrinsic action potential frequency of orexigenic arcuate nucleus neuropeptide Y/Agouti-related protein neurons. Endocrinology 146:1043-1047. CrossRef Medline

Thaler JP, Yi CX, Schur EA, Guyenet SJ, Hwang BH, Dietrich MO, Zhao X, Sarruf DA, Izgur V, Maravilla KR, Nguyen HT, Fischer JD, Matsen ME, Wisse BE, Morton GJ, Horvath TL, Baskin DG, Tschöp MH, Schwartz MW (2012) Obesity is associated with hypothalamic injury in rodents and humans. J Clin Invest 122:153-162. CrossRef Medline

Vong L, Ye C, Yang Z, Choi B, Chua S Jr, Lowell BB (2011) Leptin action on
GABAergic neurons prevents obesity and reduces inhibitory tone to POMC neurons. Neuron 71:142-154. CrossRef Medline

Wolden-Hanson T, Marck BT, Smith L, Matsumoto AM (1999) Crosssectional and longitudinal analysis of age-associated changes in body composition of male Brown Norway rats: association of serum leptin levels with peripheral adiposity. J Geront A Biol Sci Med Sci 54:B99-B107. CrossRef

Yang Y, Atasoy D, Su HH, Sternson SM (2011) Hunger states switch a flipflop memory circuit via a synaptic AMPK-dependent positive feedback loop. Cell 146:992-1003. CrossRef Medline

Zeltser LM, Seeley RJ, Tschöp MH (2012) Synaptic plasticity in neuronal circuits regulating energy balance. Nat Neurosci 15:1336-1342. CrossRef Medline 